\title{
Carbon and chlorine isotope fractionation patterns associated with different engineered
} chloroform transformation reactions

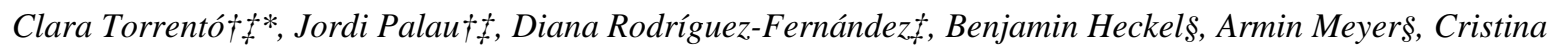

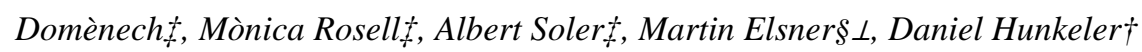

†Centre for Hydrogeology and Geothermics, Université de Neuchâtel, 2000 Neuchâtel, Switzerland. ‡Grup de Mineralogia Aplicada i Geoquímica de Fluids, Departament de Mineralogia, Petrologia i Geologia Aplicada, Facultat de Ciències de la Terra, Martí Franques s/n, Universitat de Barcelona (UB), 08028 Barcelona, Spain. §Institute of Groundwater Ecology, Helmholtz Zentrum München, 85764 Neuherberg, Germany. \lrcorner Chair of Analytical Chemistry and Water Chemistry, Technical University of Munich, Marchioninistrasse 17, D-81377 Munich, Germany.

\section{Corresponding Author:}

*Clara Torrentó Phone: +41 32718 26 49; Fax: +41 3271826 03, e-mail: clara.torrento@unine.ch

\section{Abstract}

To use compound-specific isotope analysis for confidently assessing organic contaminant attenuation in the environment, isotope fractionation patterns associated with different transformation mechanisms must first be explored in laboratory experiments. To deliver this information for the common groundwater contaminant chloroform (CF), this study investigated for the first time both carbon and chlorine isotope fractionation for three different engineered reactions: oxidative $\mathrm{C}-\mathrm{H}$ bond cleavage using heat-activated persulfate, transformation under alkaline conditions $(\mathrm{pH} 12)$ and reductive C-Cl bond cleavage by cast zero-valent iron, $\mathrm{Fe}(0)$. Carbon and chlorine isotope fractionation values were $8 \pm 1 \%$ and $-0.44 \pm 0.06 \%$ for oxidation, $-57 \pm 5 \%$ o and $-4.4 \pm 0.4 \%$ for alkaline hydrolysis $(\mathrm{pH}=$ $11.84 \pm 0.03$ ), and $-33 \pm 11 \%$ and $-3 \pm 1 \%$ or dechlorination, respectively. Carbon and chlorine apparent kinetic isotope effects (AKIEs) were in general agreement with expected mechanisms (C-H bond cleavage in oxidation by persulfate, $\mathrm{C}$ - $\mathrm{Cl}$ bond cleavage in $\mathrm{Fe}(0)$-mediated reductive dechlorination and $\mathrm{E}_{\mathrm{CB}}$ elimination mechanism during alkaline hydrolysis) where a secondary $\mathrm{AKIE}_{\mathrm{Cl}}$ (1.00045 \pm 0.00004$)$ was observed for oxidation. The different dual carbon-chlorine $\left(\Delta \delta^{13} \mathrm{C}\right.$ vs. $\left.\Delta \delta^{37} \mathrm{Cl}\right)$ isotope patterns for oxidation by thermally-activated persulfate and alkaline hydrolysis $(17 \pm 2$ and 
$13.0 \pm 0.8$, respectively) vs. reductive dechlorination by $\mathrm{Fe}(0)(8 \pm 2)$ establish a base to identify and quantify these CF degradation mechanisms in the field.

\section{Introduction}

Chloroform (CF) is both an anthropogenic environmental contaminant widely distributed around the world as well as a natural compound formed in various aquatic and terrestrial environments ${ }^{1-3}$. CF of anthropogenic origin has been extensively used as degreasing agent and as a precursor to Teflon and various refrigerants and was historically used in medicine as anesthetic. It is formed as oxidation byproduct during drinking water treatment ${ }^{4}$ and may form as a daughter product of carbon tetrachloride (CT) dehalogenation at contaminated sites. As a result, CF is one of the most frequently detected volatile organic compounds (VOCs) in groundwater ${ }^{5}$ Taking into account its high ecotoxicity ${ }^{6}$, CF prominently ranks among the halogenated VOCs on the Agency for Toxic Substances and Disease Registry priority list of hazardous substances ${ }^{7}$.

Aerobic and anaerobic cometabolic biodegradation processes of CF have been described ${ }^{8}$. However, CF cometabolic degradation is restricted by several environmental factors such as the presence of other specific compounds that inhibit CF degradation, the availability of the substrate or the toxicity of derived metabolites ${ }^{8}$. Reductive dechlorination of CF via dehalorespiration by two Dehalobacter sp. strains (CF50 and UNSWDHB) and one Desulfitobacterium sp. strain (PR) has recently been described in laboratory studies ${ }^{9-14}$ and proposed as anaerobic bioremediation strategy. However, this strategy is only applicable to contaminated sites in the absence of its parent compound, i.e. CT, which has been shown to strongly inhibit CF dehalorespiration in an enrichment culture containing Dehalobacter spp. ${ }^{15}$. In turn, CF itself is a strong inhibitor of chlorinated ethene- or ethane-degrading cultures even when present at low concentrations ${ }^{16,17}$. These interdependencies make the remediation of sites contaminated with several chlorinated compounds particularly challenging so that multiplestage remediation strategies are warranted in which inhibitors like chloromethanes are removed upfront. 
Abiotic reactions bear potential to accomplish such an initial removal. Naturally occurring ironbearing minerals like goethite and iron sulfide under low-redox environments have been demonstrated to be involved in the reductive dechlorination of $\mathrm{CF}^{18}$. However, due to the very restricted natural attenuation conditions for $\mathrm{CF}$ and its complex distribution in the subsurface as a dense nonaqueous phase liquid (DNAPLs), more efficient engineered remediation strategies have been proposed to increase CF removal in the environment. As a result of the high oxidation state of carbon in CF, its degradation by in situ chemical oxidation (ISCO) is in general much less effective than for chlorinated ethenes using common oxidants such as permanganate, iron-activated persulfate (PS), ozone, hydrogen peroxide, or Fenton's Reagent ${ }^{19}$. However, thermally-activated PS was recently shown to be a better option for efficient CF oxidation with the advantage that under thermal activation, the strongly oxidizing sulfate radical and other reactive intermediates (i.e. hydroxyl radicals, or reducing radicals such as superoxide radicals, $\mathrm{O}_{2}{ }^{-*}$ ) can be generated at neutral $\mathrm{pH}^{20-23}$.

Alternatively, CF alkaline hydrolysis has recently been proposed as a remediation technology based on its occurrence in drainage trenches filled with concrete-based construction wastes ${ }^{24}$. For the sustainable use of this new remediation strategy, identifying and assessing the performance of CF degradation reaction by alkaline hydrolysis, as well as understanding the underlying mechanism, is important.

Finally, CF reductive dechlorination by zero-valent metals has been studied only at laboratory scale ${ }^{25-}$ ${ }^{29}$. Nevertheless, this remediation strategy has been successfully proven at field sites contaminated by chlorinated ethenes using permeable reactive barriers with micro/macro-scale $\mathrm{Fe}(0)^{30,31}$ or $\mathrm{Fe}(0)$ nanoparticle injection ${ }^{32,33}$.

Improved methods are needed to delineate the relative efficacy of the above mentioned CF remediation approaches in the field. During the last decades, compound-specific isotope analysis (CSIA) has evolved as a tool to monitor transformation reactions and to quantify the progress of natural and enhanced remediation of organic contaminants ${ }^{34,35}$. Molecules with light isotopes in the reactive position typically react slightly faster than molecules containing the heavy ones leading to a 
kinetic isotope effect (KIE). As a consequence, the heavier isotopes (e.g. ${ }^{13} \mathrm{C}$ and ${ }^{37} \mathrm{Cl}$ ) usually become enriched in the remaining substrate. For a given reaction, quantification of the extent of contaminant transformation based on stable isotope ratios requires the experimental determination of isotopic fractionation ( $\varepsilon$, see Materials and Methods part) ${ }^{36}$.

Isotopic fractionation values for transformation reactions need to be known for very practical reasons: (i) to understand what changes in isotope values can be expected in the field at all, and whether this holds promise to qualitatively detect degradation; (ii) to understand what mechanism lies behind the isotope effect, in order to subsequently chose an appropriate $\varepsilon$ value for quantification in the field.

In order to gain insight into the underlying reaction mechanism, apparent kinetic isotope effects (AKIEs) can be derived from determined $\varepsilon$ values taking into account which of the atoms in the target molecule are expected to be present at the reactive position. Comparison of the observed AKIEs to the theoretical maximum KIEs (“semiclassical Streitwieser Limits”) associated with breakage of chemical bonds, enables interpretation of occurring transition state(s) of a bond cleavage in terms of (i) primary isotope effects affecting the atoms present in the reacting bond, (ii) secondary isotope effects affecting atoms located adjacent to the reacting position ${ }^{37,38}$. Often, however, it is uncertain whether additional factors exert an influence on observable isotope fractionation such as (iii) masking due to ratelimitation in mass transfer and (iv) superimposed isotope effects of multiple reaction steps typical of enzyme catalysis or multistep chemical reactions ${ }^{39-42}$. When observable isotope fractionation of a single element varies between experiments, it is, therefore, often uncertain whether this is due to a different mechanism, or whether these other factors are responsible. Dual-element isotope plots - i.e., graphs in which changes in isotope values of one element are plotted against those of a second - offer a more reliable distinction between reaction mechanisms than $\varepsilon$ values alone ${ }^{35,39,43-50}$.

Such information can be highly valuable in field situations. Non-destructive abiotic natural processes, such as sorption, volatilization or diffusion strongly affect concentrations of a contaminant, but generally do not cause significant isotopic fractionation ${ }^{51-57}$. Temporal or spatial shifts in isotope ratios, in contrast, are highly indicative of degradation and can, therefore, better monitor the success of 
remediation strategies at contaminated sites than mass balances alone ${ }^{58}$. Dual (or multi) isotope patterns, finally, can even be used to derive the relative contribution of different reaction mechanisms and then to quantify the efficiency of each of them in the field - provided that $\varepsilon$ values of these processes have previously been characterized in laboratory experiments ${ }^{59-64}$.

Reported carbon isotope effects during CF transformation are, however, scarce in the literature. Chan et al. ${ }^{11}$ reported a carbon isotope fractionation value of $-27.5 \pm 0.9 \%$ o during dehalorespiration of CF by a mixed culture containing Dehalobacter sp. strain CF50. In comparison, a much lower $\varepsilon_{\mathrm{C}}$ value of $4.3 \pm 0.4 \%$ o was reported by Lee et al. ${ }^{29}$ for the same dechlorination reaction by a mixed consortium containing another Dehalobacter sp. strain, UNSWDHB, whereas isotope fractionation in CF abiotic reductive dechlorination by micro-sized $\mathrm{Fe}(0)$ was found to be indistinguishable from that of the first experiment (-29 $\pm 2 \%$ o). Significantly, larger carbon isotopic fractionation was observed for CF alkaline hydrolysis at $\mathrm{pH}$ ranging from 11.8 to $12.7(-53 \pm 3 \%)^{24}$. To the best of our knowledge, chlorine isotope fractionation during any CF transformation mechanism has not been reported so far. Specifically, understanding whether different reaction mechanisms lead to characteristic patterns in dual C-Cl isotope plots is still limited even for chlorinated ethenes ${ }^{46,47,62}$ and, to our knowledge, is currently non-existent for chlorinated methanes. Hence, there is a need to explore dual element CSIA for defined reactions under controlled laboratory conditions to pave the path for the interpretation of isotope data in field studies.

Therefore, the goal of this study was to determine carbon and, for the first time, chlorine isotope fractionation patterns for different transformation processes of CF in important abiotic engineered reactions in order to explore the ability of CSIA to identify these processes at field sites. The selected chemical reactions were: oxidative $\mathrm{C}-\mathrm{H}$ bond cleavage by radicals produced from PS activation, alkaline hydrolysis of chloroform at pH 12 and C-Cl bond cleavage in reductive dechlorination by cast milli-sized Fe(0).

\section{Material and methods}

\subsection{Experimental setup}


All the experiments were conducted in duplicate using glass vials completely filled with aqueous solution without headspace to avoid partitioning of chlorinated volatile compounds into the gas phase. For the experiments with heat-activated PS and alkaline hydrolysis, 21-mL vials sealed with PTFEcoated rubber stoppers and aluminum crimp seals were used, whereas the $\mathrm{Fe}(0)$ experiments were performed using 42-mL clear glass vials capped with PTFE-coated rubber stoppers and plastic screw caps. A list of chemicals and additional experiment details is available in the Supporting Information (SI).

For the thermally-activated PS experiments, the vials were filled with a $\mathrm{pH} 7$ buffer solution and 0.5 $\mathrm{mL}$ of solutions with variable concentrations of PS were added to achieve initial PS-to-CF-molar ratios of $5 / 1,10 / 1$ or $40 / 1$. The vials were placed in a thermostatic water bath at $50.0 \pm 0.5{ }^{\circ} \mathrm{C}$ and the reaction was initiated by the addition of $0.5 \mathrm{~mL}$ of an aqueous CF (99\%, Sigma-Aldrich) stock solution containing $2100 \mathrm{mg} \mathrm{L}^{-1}$ to achieve initial concentrations of $50 \mathrm{mg} \mathrm{L}^{-1}$. The experiments lasted for 10 hours and samples for analysis were collected at different time intervals. At each sampling time, the vials were removed from the water bath and immediately placed in an ice bath to quench the reaction by chilling. Samples were stored in the dark at $4{ }^{\circ} \mathrm{C}$ until analysis. Losses of CF due to volatilization and/or sorption were accounted for in control experiments set up in an identical manner except for the addition of PS.

CF alkaline hydrolysis experiments were performed at room temperature $\left(\sim 25^{\circ} \mathrm{C}\right)$ in a $\mathrm{pH} 12$ buffer solution and the vials were covered with aluminum foil to avoid photocatalyzed oxidation of CF. The reaction was initiated by the addition of $0.5 \mathrm{~mL}$ of the CF (99\%, Sigma-Aldrich) stock solution to reach initial theoretical concentrations of $50 \mathrm{mg} \mathrm{L}^{-1}$. The experiments started at different times to achieve reaction times varying from 0 to $35 \mathrm{~d}$. After $35 \mathrm{~d}$ from the earliest prepared vials, all the vials were sacrificed at the same time. An appropriate volume of $0.1 \mathrm{M}$ acetic acid was added to the vials to neutralize the solution to $\mathrm{pH} 6$ and quench the alkaline hydrolysis reaction. Samples were stored in the dark at $4{ }^{\circ} \mathrm{C}$ until analysis. Control experiments with unbuffered deionized water were also performed.

156 For the $\mathrm{Fe}(0)$ experiments, $2 \mathrm{~g}$ of milli-sized cast iron $\left(1.624 \pm 0.007 \mathrm{~m}^{2} \mathrm{~g}^{-1}\right)$ were added to each 42 -mL 157 vial to reach a surface concentration of $77 \mathrm{~m}^{2} \mathrm{~L}^{-1}$. Afterwards the vials were filled with a pH 6.6 buffer solution and the reaction was initiated by the addition of the CF pure phase (99\%, Alfa Aesar) to reach 
initial theoretical concentrations of $100 \mathrm{mg} \mathrm{L}^{-1}$. The vials were covered with aluminum foil to avoid photocatalyzed oxidation of CF and were rotated on a horizontal shaker (IKA KS 260 BASIC, Stanfen, Germany) at $200 \mathrm{rpm}$. Control experiments without iron were also carried out. The experiments were performed at room temperature $\left(\sim 25^{\circ} \mathrm{C}\right)$ and they lasted 51 hours. Reactions were stopped by filtration through $0.2 \mu \mathrm{m}$ filters at different time intervals and samples for analysis were stored frozen in $10 \mathrm{~mL}$ vials covered with aluminum foil.

\subsection{Analytical Methods}

Detailed descriptions of analytical methods are available in the SI. Briefly, concentration measurements of chlorinated compounds were performed by headspace (HS) using GC/MS as explained elsewhere ${ }^{24}$, except for the samples from $\mathrm{Fe}(0)$ experiments for which GC/TOF/MS was used. Chloride anion concentrations were analyzed by high-performance liquid chromatography. Carbon isotope analyses of CF and some detectable volatile daughter products were performed using two different GC/IRMS systems located at the University of Neuchâtel (GC/IRMS-1) ${ }^{50}$ and at the Scientific and Technological Centers of the University of Barcelona (GC/IRMS-2) ${ }^{24}$. Chlorine isotope CF analyses were performed using a GC/qMS system from the University of Neuchâtel as explained elsewhere ${ }^{66}$ or a GC/IRMS system from the Institute of Groundwater Ecology of the Helmholtz Zentrum München (GC/IRMS-3). An interlaboratory comparison demonstrating excellent agreement between the two analytical methods is provided in Heckel et al. ${ }^{67}$.

\subsection{Isotope data evaluation}

Bulk carbon and chlorine $\varepsilon$ values were obtained from the slope of the linearized Rayleigh equation for a closed system ${ }^{36}$ :

$$
\ln \left(\frac{\delta_{\mathrm{t}}+1}{\delta_{0}+1}\right)=\varepsilon \times \ln \mathrm{f}
$$


delta notation relative to international standards, i.e. Vienna PeeDee Belemnite for carbon $\left(\delta^{13} C_{\text {vpDB }}\right)$ and the international Standard Mean Ocean Chloride (SMOC) for chlorine $\left(\delta^{37} \mathrm{Cl}_{\text {SMOC }}\right)$ :

$$
\delta(\text { in } \%)=\left(R / R_{\text {std }}-1\right)
$$

where $\mathrm{R}$ and $\mathrm{R}_{\text {std }}$ are the isotope ratios of the sample and the standard, respectively.

Errors given for $\varepsilon$ values are the $95 \%$ confidence intervals (CI) of the slope of the regression line in the Rayleigh plots.

The apparent kinetic isotope effects (AKIEs) were calculated to evaluate the intrinsic isotope effect of the bond cleavage (see equations in the SI).

For dual C-Cl isotope plots, the slope of the correlation trend was determined by linear regression and the uncertainty corresponds to the $95 \%$ CI.

\section{Results and discussion}

\subsection{Carbon and chlorine isotope fractionation}

Changes in $\mathrm{CF}$ concentration and $\mathrm{C}$ and $\mathrm{Cl}$ isotope ratios of $\mathrm{CF}$ during degradation by the three different mechanisms are shown in Figure 1. No CF degradation was observed in the experimental controls (without adding PS, $\mathrm{Fe}(0)$ or at neutral $\mathrm{pH}$ in the case of the hydrolysis reaction) for any of the three studied reactions. Measured concentrations in all the samples from the control experiments were always higher than $80 \%$ of the initial CF concentration (Fig 1). Accordingly, no significant changes in $\delta^{13} \mathrm{C}$ and $\delta^{37} \mathrm{Cl}$ isotope values were detected in the control experiments. In the rest of the experiments, a normal isotope effect was observed for both carbon and chlorine. The isotope results of combined experimental replicates, which were highly consistent for each experimental system, were used to derive $\mathrm{C}$ and $\mathrm{Cl}$ isotope fractionation values by the use of Rayleigh plots (Fig 2 and Fig S3). Further details on kinetics data evaluation, comparison with previous studies and product yields are provided in the SI. 
PS oxidation. The initial carbon and chlorine isotope composition remained constant (-42 $\pm 1 \%$ and $3.1 \pm 0.2 \%$, respectively, both $\mathrm{n}=4$ ) in the control experiments (Fig S3A, B). Around $90 \%$ of $\mathrm{CF}$ removal was observed after 6 days in the PS experiments with an initial PS/CF molar ratio of 40/1 (Fig 1A). In contrast, only $30 \%$ and $20 \%$ of CF degradation were accomplished after 7 days with initial molar ratios of 10/1 and 5/1, respectively (Fig. S1). Therefore, isotope ratios were determined only in those samples from the experiments with an initial PS to CF molar ratio of 40/1. Carbon isotope fractionation during oxidation with PS has been shown to be independent of the PS/contaminant molar ratio for chlorinated ethenes and 1,1,1-trichloroethane. ${ }^{68,69}$ Carbon isotope composition exhibited an enrichment of ${ }^{13} \mathrm{C} /{ }^{12} \mathrm{C}$ up to $\delta^{13} \mathrm{C}$ values of $-23.8 \pm 0.5 \%$, which resulted in an $\varepsilon_{\mathrm{C}}$ value of $-8 \pm 1 \%$ (Fig 2A). Compared to carbon, a much smaller shift in ${ }^{37} \mathrm{Cl} /{ }^{35} \mathrm{Cl}$ was observed (Fig $1 \mathrm{~A}$ ), resulting in $\delta^{37} \mathrm{Cl}$ values up to $-1.9 \pm 0.4 \%$ o (Fig S3AB). An $\varepsilon_{\mathrm{Cl}}$ of $-0.44 \pm 0.06 \%$ was obtained (Fig 2B). Neither carbon nor chlorine isotope fractionation associated with this reaction have been reported so far. The $\mathrm{pH}$ was kept at circumneutral values (7.0 \pm 0.2$)$ during the course of the experiment. This reaction followed pseudo-first-order kinetics with a k' of $0.40 \pm 0.06 \mathrm{~d}^{-1}\left(\mathrm{R}^{2}=0.96\right.$, Fig S1). Neither PS consumption nor sulfate production were monitored along the experiments. Chloride concentrations released into solution were measured at the end of the experiment and accounted for between 95\% and 110\% of the total theoretical CF dechlorination yield, which was calculated assuming release of all the three chlorine atoms. Neither products nor intermediates were detected by headspace GC/MS analysis during the course of the experiments.

Alkaline hydrolysis. Carbon and chlorine isotope values remained constant (-41.8 $\pm 0.5 \%$ and $2.6 \pm 0.4 \%$, respectively both $\mathrm{n}=5$ ) in control vials at neutral $\mathrm{pH}$. Under alkaline conditions (the $\mathrm{pH}$ remained constant $11.84 \pm 0.03$ over the duration of the experiment), a $85 \%$ decrease in $\mathrm{CF}$ concentration within approximately 35 days was observed (Fig 1B). Alkaline hydrolysis induced a significant isotope effect, resulting in $\delta^{13} \mathrm{C}$ and $\delta^{37} \mathrm{Cl}$ values up to $+70.6 \pm 0.3 \%$ and $+5.7 \pm 0.4 \%$, respectively, after $85 \%$ CF removal (Fig S3C, D). An $\varepsilon_{\mathrm{C}}$ of $-57 \pm 5 \%$ (Fig $2 \mathrm{C}$ ) and $\varepsilon_{\mathrm{Cl}}$ of $-4.4 \pm 0.4 \%$ (Fig 2D) were determined. So far, the only reported carbon isotope fractionation value for CF alkaline hydrolysis was $-53 \pm 3 \%$ at a $\mathrm{pH}$ range from 11.9 to 12.7$)^{24}$, which is comparable, within uncertainty, 
to that obtained in the present study. Carbon isotope fractionation is therefore independent of the $\mathrm{pH}$ in the tested range (from 11.8 to 12.7). To our knowledge chlorine isotope fractionation for this reaction has not been reported up to now.. The reaction followed pseudo-first-order kinetics $\left(\mathrm{R}^{2}=0.92\right.$, Fig $\left.\mathrm{S} 1\right)$ with a k' of $0.052 \pm 0.008 \mathrm{~d}^{-1}$, which is in agreement with a previously reported rate constant of $0.047 \pm 0.004 \mathrm{~d}^{-1}$ obtained at a similar $\mathrm{pH} 11.9 \pm 0.1^{24}$. No particular attempts were made to identify potential products of $\mathrm{CF}$ degradation, such as carbon monoxide (CO), formate $\left(\mathrm{HCO}_{2}^{-}\right)$, and chloride $\left(\mathrm{Cl}^{-}\right)$. In our previous work, excellent chlorine balances were achieved in similar experiments, indicating that CF was completely dehalogenated without accumulation of chlorinated intermediates ${ }^{24}$.

$\underline{\mathrm{Fe}(0)}$ dechlorination. $\mathrm{CF}$ in the controls without $\mathrm{Fe}(0)$ at $\mathrm{pH} 6.3 \pm 0.2$ did not show any changes in carbon and chlorine isotope composition $\left(\delta^{13} \mathrm{C}=-47.8 \pm 0.5 \%, \mathrm{n}=4\right.$ and $\delta^{37} \mathrm{Cl}=-3.2 \pm 0.2 \%$, $\mathrm{n}=6$, respectively). In the presence of milli-sized $\mathrm{Fe}(0)$, CF isotope signatures of both elements showed significant changes leading up to values of $\delta^{13} \mathrm{C}=+35.9 \pm 0.5 \%$ and $\delta^{37} \mathrm{Cl}=+1.7 \pm 0.1 \%$, respectively, after $84 \%$ CF removal (Fig S3E, F). Isotope fractionation values of $\varepsilon_{\mathrm{C}}=-33 \pm 11 \%$ and $\varepsilon_{\mathrm{Cl}}=-3 \pm 1 \%$ o were determined (Fig $2 \mathrm{E}$ and $\mathrm{F}$ ). The obtained $\varepsilon_{\mathrm{C}}$ was not significantly different from $\varepsilon_{\mathrm{C}}$ of $-29 \pm 2 \%$ reported recently after $50 \%$ of CF dechlorination by commercial micro-sized $\mathrm{Fe}(0)^{29}$. Chlorine isotope fractionation associated with this reaction has not been reported yet. The $\mathrm{pH}$ did not vary significantly over the duration of the experiment (6.2 \pm 0.2$)$. The degradation kinetics followed a pseudo-first-order rate law at the beginning of the reaction but after 30 hours the disappearance of CF almost stopped (Fig 1C). For Fe(0)-mediated dechlorination of chlorinated ethenes, iron surface passivation due to reactive site saturation by iron hydroxide precipitates has been suggested as the cause of increased reaction half-lives and deviations from pseudo-first-order kinetics at later stages of a reaction ${ }^{70}$. The obtained $k^{\prime}$ was $0.07 \pm 0.01 \mathrm{~h}^{-1}\left(\mathrm{R}^{2}=0.93\right.$, Fig S1), which corresponds to a $\mathrm{k}_{\mathrm{SA}}$ of $2.1 \pm 0.4 \times 10^{-2} \mathrm{~L} \mathrm{~m}^{-2} \mathrm{~d}^{-1}$ (see SI).

DCM and free chloride were detected as final products in $\mathrm{Fe}(0)$ experiments, whereas no compounds different from CF appeared in the control experiments without iron. The yield of DCM, defined as the moles of product formed per mole of CF transformed $\left(\mathrm{DCM}_{t} /\left(\mathrm{CF}_{0}-\mathrm{CF}_{\mathrm{t}}\right)\right)$, where subscripts 0 and $t$ indicate initial time and different sampling times, respectively) ranged from 0 to $2.4 \%$ over time, 
showing that accumulation of DCM only accounted for a small fraction of the initial CF. DCM was depleted in ${ }^{13} \mathrm{C}$ compared to the initial isotopic composition of the substrate (CF). DCM showed a trend towards higher $\delta^{13} \mathrm{C}$ values, reflecting the enrichment trend of the $\mathrm{CF}$ from which it was formed (Fig S3E). The DCM-related isotope fractionation $\varepsilon_{\text {substrate } \rightarrow \text { product }}^{C_{\text {was }}}$ wastimated as $-19 \pm 3 \%$ o using the fitting parameter, $\mathrm{D}\left(\delta^{13} \mathrm{C}\right)=+13 \pm 2 \%$ o $\left(\mathrm{R}^{2}=0.62\right)$ (see equations in the SI). This discrepancy between the product-related and the substrate-related isotope fractionations $\left(\varepsilon^{\mathrm{C}}{ }_{\mathrm{CF} \rightarrow \mathrm{DCM}}=-19 \pm 3 \%\right.$ vs. $\varepsilon_{\mathrm{C}}=-$ $33 \pm 11 \%$ ) is likely attributable to the formation of other products including isotope-sensitive branching from the parent compound or intermediates, such as a dichloromethyl radical (Fig S4), to $\mathrm{DCM}^{71}$. However, due to the lack of DCM isotope signatures at early stages of reaction, such interpretations must be conducted with caution.

\subsection{Mechanistic considerations}

For further elucidation of the reaction mechanism, AKIE values were calculated using Eq. SI6, to characterize the isotope effect of the cleavage of the chemical bond at the reactive positions. Table 1 summarizes the obtained results and proposed reaction pathways for the three studied reactions are shown in Figure 3 and discussed in detail in the SI.

The $\mathrm{AKIE}_{\mathrm{C}}$ for the oxidation reaction was $1.008 \pm 0.001$, which is within the range of reported carbon AKIEs for oxidative C-H bond cleavage for both abiotic (1.008-1.015) and microbial oxidation reactions (1.001-1.044) (Table S2), indicating that the observed fractionation was dominated by the KIE associated with oxidative cleavage of a C-H bond. A similar $\mathrm{AKIE}_{\mathrm{C}}$ value (1.008) was obtained for 1,1,1-TCA oxidation by thermally-activated $\mathrm{PS}^{65}$ from which it was suggested that the first reaction step was the rupture of the $\mathrm{C}-\mathrm{H}$ bond and the abstraction of the hydrogen atom from the 
molecule by the attack of any of the radicals formed after persulfate activation ${ }^{65,72,73}$. The secondary $\mathrm{AKIE}_{\mathrm{Cl}}$ estimated in the present experiments $(1.00045 \pm 0.00004)$ also points to an oxidative reaction, where there is not initial $\mathrm{C}-\mathrm{Cl}$ bond cleavage and thus a primary chlorine kinetic isotope effect is not expected. A reaction pathway involving the cleavage of the $\mathrm{C}-\mathrm{H}$ as the rate-limiting step is proposed (Fig 3A and SI). In order to track more confidently the proposed mechanism, hydrogen isotope fractionation during CF oxidation with thermally-activated PS might be further measured.

During alkaline hydrolysis, CF is abiotically dechlorinated to carbon monoxide and formate ${ }^{74,75}$. A stepwise elimination mechanism $\left(\mathrm{E} 1_{\mathrm{CB}}\right)$ has been proposed for this reaction ${ }^{24,74,76,77}$. This mechanism consists of the rapid, reversible, base-catalyzed deprotonation of the molecule with the formation of a trichloromethyl carbanion $\left(: \mathrm{CCl}_{3}{ }^{-}\right)$, followed by the rate-determining unimolecular loss of a chloride ion to produce the reactive intermediate dichlorocarbene $\left(\mathrm{CCl}_{2}\right)$, which is then rapidly transformed into carbon monoxide and formate (Fig S4). If this is the case, as the deprotonation step is reversible and the loss of a chloride ion is the rate-determining step, both carbon and chlorine primary isotope effects in the CF molecule are expected during this process. In the present experiments, an $\mathrm{AKIE}_{\mathrm{C}}$ of $1.061 \pm 0.006$ was obtained for alkaline hydrolysis, which is consistent with the Streitwieser limit for a primary carbon KIE in C-Cl bonds (1.057, Table S2) ${ }^{37,78}$ and is equivalent, within the given 95\% CI, to the value previously found by Torrentó et al. ${ }^{24}(1.056 \pm 0.003)$. The AKIE $E_{C l}$ was calculated as $1.0133 \pm 0.0004$, which is equal to the maximum expected $\mathrm{KIE}_{\mathrm{Cl}}$ for cleavage of a $\mathrm{C}-\mathrm{Cl}$ bond (1.013, Table S2) ${ }^{37}$, indicating the involvement of a C-Cl bond. In principle, the $\mathrm{Cl}$ kinetic isotope effect estimated in the present study is, therefore, consistent with the occurrence of a carbanion mechanism (Fig 3A) but also with a C-Cl bond cleavage via a concerted one-step $\mathrm{S}_{\mathrm{N}} 2$ nucleophilic substitution mechanism. Nevertheless, based on energy considerations, the $\mathrm{E} 1_{\mathrm{CB}}$ mechanism seems more plausible for this reaction (see the SI for further discussion). Further deuterium-exchange experiments might be performed to confirm the existence of a carbanion intermediate as a way to further corroborate the occurrence of the stepwise elimination mechanism ${ }^{79}$.

In the case of reductive dechlorination by $\mathrm{Fe}(0)$, an $\mathrm{AKIE}_{\mathrm{C}}$ of $1.034 \pm 0.012$ was obtained, which is similar to the value of $1.030 \pm 0.007$ obtained by Lee et al. ${ }^{29}$ and within the $A K I E_{C}$ range for the 
reductive cleavage of $\mathrm{C}-\mathrm{Cl}$ bonds reported in the literature (1.003-1.060) (Table S2). In fact, most AKIE $_{\mathrm{C}}$ values for reductive dehalogenation fall in the range of 1.027 and 1.033 , which corresponds to about 50\% bond cleavage when considering a Streitwieser limit for a C-Cl bond of 1.057 for complete bond cleavage in an infinitely late transition state ${ }^{80}$. Regarding $\mathrm{AKIE}_{\mathrm{Cl}}$, a value of $1.008 \pm 0.001$ was calculated, which is also about $50 \%$ of the Streitwieser limit for $\mathrm{KIE}_{\mathrm{Cl}}$ in C-Cl bonds $(1.013)^{37}$. Similar $\mathrm{AKIE}_{\mathrm{Cl}}$ values, ranging from 1.008 to 1.016 for abiotic reductive dechlorination and from 1.004 to 1.011 for biotic reductive dechlorination, have been previously reported for chlorinated methanes, ethenes and ethanes (Table S2). Therefore, both $\mathrm{C}$ and Cl-AKIEs pointed to cleavage of a C-Cl bond in the first rate-limiting step, which is compatible with the two-step pathway that is commonly hypothesized for this reaction (see SI). The first step may, for example, involve the transfer of a single electron from the metal surface causing the removal of a chlorine atom and the formation of a dichloromethyl radical $\left(\cdot \mathrm{CHCl}_{2}\right)$ (Fig 3A).

\subsection{Dual element isotope plot}

Figure 3B shows the dual C-Cl isotope plot for the reactions of this study. A linear correlation between $\Delta \delta^{13} \mathrm{C}$ and $\Delta \delta^{37} \mathrm{Cl}$ was observed for the three studied transformation mechanisms $\left(\mathrm{r}^{2} \geq 0.92\right)$. A comparison of the slopes $\left(\Lambda=\Delta \delta^{13} \mathrm{C} / \Delta \delta^{37} \mathrm{Cl}\right)$ for the regression lines was performed by analysis of covariance (ANCOVA). Statistical significance was accepted at the $\mathrm{p}<0.05$ level. There is no

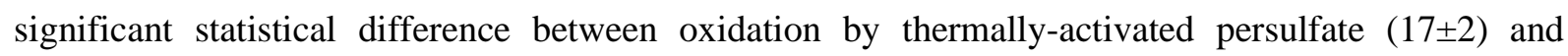
alkaline hydrolysis (13.0 \pm 0.8 ) slopes (ANCOVA, $\mathrm{p}=0.2$ ). In contrast, these results differ significantly (ANCOVA, $\mathrm{p}<0.0001)$ from the slope observed during CF reductive dechlorination by $\mathrm{Fe}(0)(8 \pm 2)$.

Hence, although different mechanisms are involved in CF degradation by oxidation by thermallyactivated PS (cleavage of a C-H bond) and by alkaline hydrolysis (cleavage of a C-Cl bond), the obtained $\Lambda$ values for both degradation reactions are not significantly different. This may be explained by considerations for carbon and chlorine isotope effects. Carbon. As expected, the obtained $\mathrm{AKIE}_{\mathrm{C}}$ value for CF degradation by oxidation with heat-activated PS is smaller than for alkaline hydrolysis. The higher the mass of the bonding partner, the greater is typically the primary kinetic isotope 
effects $^{37}$. Hence it can be explained that carbon isotope fractionation associated with C-Cl bond cleavage is greater than in $\mathrm{C}-\mathrm{H}$ bond cleavage since the carbon atom is bound to a heavier atom (chlorine vs. hydrogen). Chlorine. This difference, however, is matched by similar differences in chlorine isotope fractionation. On the one hand, $\mathrm{C}-\mathrm{Cl}$ bond cleavage involves a primary $\mathrm{AKIE} \mathrm{Cl}_{\mathrm{Cl}}$ which is clearly greater than a secondary $\mathrm{AKIE}_{\mathrm{Cl}}$ next to a reacting $\mathrm{C}-\mathrm{H}$ bond. On the other hand, this primary $\mathrm{AKIE}_{\mathrm{Cl}}$ is "diluted" in $\varepsilon_{\mathrm{Cl}}$ due to the intramolecular competition between three chemically equivalent $\mathrm{C}-\mathrm{Cl}$ bonds ( $\mathrm{z}=3$ in Eq. SI6), whereas the simultaneous secondary $\mathrm{AKIE} \mathrm{El}_{\mathrm{Cl}}$ of three $\mathrm{Cl}$ atoms are not diluted $(\mathrm{z}=1)$. By coincidence, the interplay of these factors results in a similar reduction of carbon as of chlorine isotope fractionation so that similar $\Lambda$ are obtained. This unexpected result restrains the use of $\mathrm{C}-\mathrm{Cl}$ isotope plots for distinguishing these reactions in the field and highlights the need to apply this approach with precaution and using complementary tools for identification of degradation mechanisms in the field (e.g., complementary hydrogen isotope analysis).

\section{Environmental significance}

Carbon and chlorine isotope fractionation of CF during oxidation with heat-activated PS, by alkaline hydrolysis and by reductive dechlorination with $\mathrm{Fe}(0)$ was studied in batch experiments in order to explore the potential of CSIA for the identification of reaction mechanisms in the monitoring of remediation strategies at contaminated sites. For the first time, carbon isotope fractionation values (for heat-activated PS) and chlorine isotope fractionation values (for the three reactions) were determined. These new $\varepsilon$ values increase the options of using CSIA for estimating the extent of contaminant degradation at field sites where remediation strategies are implemented that rely on induced abiotic transformations of CF. Based on the obtained $\varepsilon$ values, it is likely that changes in isotope values in the field may be larger than 2\%o for carbon and 0.4\% (for GC/IRMS instruments) or 2\%o (for GC/qMS instruments) for chlorine - these are the significant levels that have been suggested as reliable indicators of degradation ${ }^{34,81}$. Even with the relatively small carbon fractionation obtained for CF oxidation by PS (-8 $\pm 1 \%$ ) and chlorine isotope fractionation observed for $\mathrm{Fe}(0)$-mediated reductive dechlorination ( $-3 \pm 1 \%$ ), shifts in CF isotopic composition will be already detectable with a reasonable accuracy if the substrate is degraded by $20 \%$ and $25-50 \%$, respectively. 
Although only the reductive dechlorination showed significantly statistically different C-Cl isotope slope compared with the other two reactions (oxidation and alkaline hydrolysis), the dual isotope approach might still be used to identify different CF degradation mechanisms in the field, which would (or not necessarily) take place at the same time. For example, the coupling of two common treatments—ISCO and in situ bioremediation — has been shown not only to be feasible, but in many cases also to be able to provide a more efficient and extensive cleanup of contaminated sites ${ }^{82}$. In the case of PS, the anaerobic environment that is created following the consumption of the oxidant is ideal

372 for CF microbial dehalogenation under sulfate reduction conditions to be enhanced. Enhanced CF bioremediation has also been observed when combining $\mathrm{Fe}(0)$ and methanogens that use the cathodic hydrogen generated by iron corrosion for cometabolic degradation of $\mathrm{CF}^{83-85}$ or even better by dehalorespiring bacteria which are not inhibited at certain concentrations of $\mathrm{CF}^{29}$. Therefore, there would be an increasing number of case studies, where CF degradation due to PS application or $\mathrm{Fe}(0)$

377 barriers should be distinguished from biotic reductive dechlorination in the field. Although chlorine 378 isotope fractionation during biotic CF dechlorination remains to be evaluated in detail, as well as the 379 effect in $\mathrm{CF}$ degradation of $\mathrm{Fe}(0)$ aging or the presence of $\mathrm{Fe}(0)$ impurities such as graphite ${ }^{86}$, the dual 380 C-Cl slopes obtained in the present work sets the grounds for the potential application of this approach 381 for assessing if CF abiotic reductive dechlorination performed by Fe(0)-PRB or naturally occurring iron-bearing minerals would be or not distinguishable from microbial reductive dechlorination.

Although CF anaerobic biodegradation has been reported to occur mainly via cometabolic dechlorination or by dehalorespiration ${ }^{8}$, an alternative pathway was suggested in the presence of cobalamins and involving CF hydrolysis ${ }^{87,88}$. The mechanism of this reaction is not well-known, but it presumably involves the cobalamin-catalyzed conversion of CF to a monochlorocarbene, which would

387 be subsequently hydrolyzed to formaldehyde. The produced formaldehyde could then be oxidized to $388 \mathrm{CO}$ or formate and finally to $\mathrm{CO}_{2}$. The abiotic alkaline hydrolysis reaction characterized in the present 389 study might be used as a reference system for this suggested CF biotic hydrolysis in future dual 390 isotope-CSIA studies. 
Finally, due to the significant difference between the $\mathrm{C}-\mathrm{Cl}$ isotope slope of $\mathrm{CF}$ oxidation and

392 reductive dechlorination, the dual isotope approach might be in addition useful for distinguishing

393 between aerobic and anaerobic CF biodegradation pathways. CF aerobic biodegradation only occurs

394 during oxidative cometabolism with other primary substrates such as methane, butane or toluene by

395 oxygenase-expressing microorganisms ${ }^{8}$. The pathway of CF cooxidation starts by insertion of one

396 oxygen atom into the molecule via $\mathrm{H}$ abstraction with phosgene as intermediate and final

397 mineralization to chloride and $\mathrm{CO}_{2}$. The chemical mechanism of CF oxidation is variable among the

398 various existent monooxygenases, but the rate-limiting step is expected to be the cleavage of the C-H 399 bond.

400 In conclusion, our study established an expedient base with carbon and chlorine isotope fractionation

401 during three abiotic CF transformation mechanisms. Further research is needed in order to explore if 402 other CF natural degradation pathways (for example naturally occurring iron-bearing minerals as well 403 as aerobic and anaerobic degraders) might be similar to or different from the patterns generated in this 404 study. Such information will allow connecting dual-plot slopes to known reaction mechanisms with 405 the aim to distinguish different degradation processes in the field. This distinction would be important 406 for better monitoring the success of remediation strategies at contaminated sites.

407 Supporting Information. Chemicals; analytical methods; further discussion in kinetics; calculation of 408 AKIE values; calculation of isotope trend for DCM in the Fe(0) experiment; carbon and chlorine 409 isotope fractionation patterns; further discussion in reaction pathways; comparison of $\varepsilon$ and AKIE 410 values for $\mathrm{C}$ and $\mathrm{Cl}$ isotopes in different studies.

\section{Acknowledgments}

412 This study was financed through the following projects: CGL2011-29975-C04-01 and CGL2014413 57215-C4-1-R from the Spanish Government, 2014SGR1456 from the Catalan Government and a 414 Marie Curie Career Integration Grant in the framework of the IMOTEC-BOX project (PCIG9-GA415 2011-293808) within the European Union 7th Framework Programme. The experiments and analysis performed in Helmholtz Zentrum München by D. Rodríguez-Fernández were supported by the 
FPU2012/01615 contract. We want to thank the Scientific and Technological Centers of the University

418 of Barcelona (CCiTUB) for their services. We thank the editor and three anonymous reviewers for 419 comments that improved the quality of the manuscript.

\section{References}

421 1. Laturnus, F.; Haselmann, K.F.; Borch, T.; Gron, C. Terrestrial natural sources of trichloromethane (chloroform, CHCl3) - An overview. Biogeochemistry 2002, 60, 121-139

2. $\quad$ Albers, C. N.; Jacobsen, O. S.; Flores, E. M. M.; Pereira, J. S. F.; Laier, T. Spatial variation in natural formation of chloroform in the soils of four coniferous forests. Biogeochemistry 2011, $103,317-334$

3. Hunkeler, D.; Laier, T.; Breider, F.; Jacobsen, O. S. Demonstrating a natural origin of

4. Rossberg, M.; Lendle, W.; Pfleiderer, G.; Tögel, A.; Torkelson, T.R.; Beutel, K.K. Chloromethanes. Ullmann's Encyclopedia of Industrial Chemistry, 2011

5. Zogorski, J.S.; Carter, J.M.; Ivahnenko, T.; Lapham, W.W.; Moran, M.J.; Rowe, B.L.; Squillace, P.J.; Toccalino, P.L. The quality of our Nation's waters - Volatile organic compounds

6. Dobrzyńska, E.; Pośniak, M.; Szewczyńska, M.; Buszewski, B. Chlorinated volatile organic compounds: Old, however, actual analytical and toxicological problem. Crit. Rev. Anal. Chem.

7. Agency for toxic substances and disease registry (ATSDR). Priority List of Hazardous dichloromethane by a Dehalobacter population._Environ. Microbiol. 2010, 12, 1053-1060 
10. Lee, M.; Low, A.; Zemb, O.; Koenig, J.; Michaelsen, A.; Manefield, M. Complete chloroform dechlorination by organochlorine respiration and fermentation. Environ. Microbiol. 2012, 14, 883-894

11. Chan, C.C.H.; Mundle, S.O.C.; Eckert, T.; Liang, X.; Tang, S.; Lacrampe-Couloume, G.; Edwards, E.A.; Sherwood-Lollar, B. Large carbon isotope fractionation during biodegradation of chloroform by Dehalobacter cultures. Environ. Sci. Technol. 2012, 46, 10154-10160

12. Tang, S.; Edwards, E.A. Identification of Dehalobacter reductive dehalogenases that catalyse dechlorination of chloroform, 1,1,1-trichloroethane and 1,1-dichloroethane. Phil. Trans. R. Soc. B 2013, 368, 20120318

13. Deshpande, N.P.; Wong, Y.K.; Manefield, M.; Wilkins, M.R.; Lee, M. Genome sequence of Dehalobacter UNSWDHB, a chloroform dechlorinating bacterium. Genome Announc. 2013, 1, e00720-13

14. Ding, C.; Zhao, S.; He, J. A Desulfitobacterium sp. strain PR reductively dechlorinates both 1,1,1-trichloroethane and chloroform. Environm. Microbiol. 2014, 16, 3387-3397

15. Justicia-Leon, S.D.; Higgins, S.; Mack, E.E.; Griffiths, D.R.; Tang, S.; Edwards, E.A.; Löffler, F.E. Bioaugmentation with distinct Dehalobacter strains achieves chloroform detoxification in microcosms. Environ. Sci. Technol. 2014, 48, 1851-1858

16. Duhamel, M.; Wehr, S.D.; Yu, L.; Rizvi, H.; Seepersad, D.; Dworatzek, S.; Cox, E.E.; Edwards, E.A. Comparison of anaerobic dechlorinating enrichment cultures maintained on tetrachloroethene, trichloroethene, cis-dichloroethene and vinyl chloride. Water Res. 2002, 36, 4193-4202

17. Maymó-Gatell, X.; Nijenhuis, I.; Zinder, S. H. Reductive dechlorination of cis-1,2dichloroethene and vinyl chloride by Dehalococcoides ethenogenes. Environ. Sci. Technol. 2001, 35, 516-521

18. Kenneke, J.F.; Weber, E.J. Reductive dehalogenation of halomethanes in iron- and sulfatereducing sediments. 1. Reactivity pattern analysis. Environ. Sci. Technol. 2003, 37, 713-720 
19. Huling, S.G.; Pivetz, B.E. In situ chemical oxidation-Engineering issue. EPA/600/R-06/072. U.S. Environmental Protection Agency Office of Research and Development, National Risk Management Research Laboratory: Cincinnati, OH, 2006

20. Huang, K.C.; Zhao, Z.; Hoag, G.E.; Dahmani, A.; Block, P.A. Degradation of volatile organic compounds with thermally activated persulfate oxidation. Chemosphere 2005, 61, 551-560

21. Waldemer, R.H.; Tratnyek, P.G.; Johnson, R.L.; Nurmi, J.T. Oxidation of chlorinated ethenes by heat-activated persulfate: Kinetics and products. Environ. Sci. Technol. 2007, 41, 1010-1015

22. Tsitonaki, A.; Petri, B.; Crimi, M.; Mosbaek, H.; Siegrist, R.L.; Bjerg, P.L. In situ chemical oxidation of contaminated soil and groundwater using persulfate: a review. Crit. Rev. Env. Sci. Tec. 2010, 40, 55-91

23. Zhu, X.; Du, E.; Ding, H.; Lin, Y.; Long, T.; Li, H.; Wang, L. QSAR modeling of VOCs degradation by ferrous-activated persulfate oxidation. Desalin. Water Treat. 2015, 1-15

24. Torrentó, C.; Audí-Miró, C.; Bordeleau, G.; Marchesi, M.; Rosell, M.; Otero, N.; Soler, A. The use of alkaline hydrolysis as a novel strategy for chloroform remediation: feasibility of using urban construction wastes and evaluation of carbon isotopic fractionation. Environ. Sci. Technol. 2014, 48, 1869-1877

25. Gillham, R.W.; OHannesin, S.F. Enhanced reduction of halogenated aliphatics by zero-valent iron. Ground Water 1994, 32, 958-967

26. Matheson, L.J.; Tratnyek, P.G. Reductive dehalogenation of chlorinated methanes by iron metal. Environ. Sci. Technol. 1994, 28, 2045-2053

27. Johnson, T.L.; Scherer, M.M.; Tratnyek, P.G. Kinetics of halogenated organic compound reduction by iron metal. Environ. Sci. Technol. 1996, 30, 2634-2640

28. Feng, J.; Lim, T.-T. Pathways and kinetics of carbon tetrachloride and chloroform reductions by nano-scale $\mathrm{Fe}$ and $\mathrm{Fe} / \mathrm{Ni}$ particles: comparison with commercial micro-scale $\mathrm{Fe}$ and $\mathrm{Zn}$. Chemosphere 2005, 59, 1267-1277

29. Lee, M.; Wells, E.; Wong, Y.K.; Koenig, J.; Adrian, L.; Richnow, H.H.; Manefield, M. Relative contributions of Dehalobacter and zerovalent Iron in the degradation of chlorinated methanes. Environ. Sci. Technol. 2015, 49, 4481-4489 
30. O’Hannesin, S.F.; Gillham, R.W. Long-term performance of an in Situ "iron wall" for remediation of VOCs. Groundwater 1998, 36, 164-170

31. Wilkin, R.T.; Acree, S.D.; Ross, R.R.; Puls, R.W.; Lee, T.R.; Woods, L.L. Fifteen-year assessment of a permeable reactive barrier for treatment of chromate and trichloroethylene in groundwater. Sci. Total Environ. 2014, 468-469, 186-194

32. Zhang, W.-X. Nanoscale iron particles for environmental remediation: An overview. J. Nanopart. Res. 2003, 5, 323-332

33. Elsner, M.; Lacrampe-Couloume, G.; Mancini, S.A.; Burns, L.; Sherwood Lollar, B. Carbon isotope analysis to evaluate nanoscale $\mathrm{Fe}(0)$ treatment at a chlorohydrocarbon contaminated site. Ground Water Monit. R. 2010, 30, 79-95

34. Meckenstock, R.U.; Barbara Morasch, B.; Griebler, C.; Richnow, H.H. Stable isotope fractionation analysis as a tool to monitor biodegradation in contaminated aquifers. J. Contam. Hydrol. 2004, 75, 215-255

35. Elsner, M. Stable isotope fractionation to investigate natural transformation mechanisms of organic contaminants: principles, prospects and limitations. J. Environ. Monitor. 2010, 12, 2005-2031

36. Mariotti, A.; Germon, J. C.; Hubert, P.; Kaiser, P.; Letolle, R.; Tardieux, A.; Tardieux, P. Experimental determination of nitrogen kinetic isotope fractionation: Some principles; illustration for the denitrification and nitrification processes. Plant Soil 1981, 62, 413-430

37. Elsner, M.; Zwank, L.; Hunkeler, D.; Schwarzenbach, R.P. A new concept linking observable stable isotope fractionation to transformation pathways of organic pollutants. Environ. Sci. Technol. 2005, 39, 6896-6916

38. Hofstetter, T.B.; Berg, M. Assessing transformation processes of organic contaminants by compound-specific stable isotope analyses. TrAC-Trends Anal. Chem. 2011, 30, 618-627

39. Mancini, S.A.; Hirschorn, S.K.; Elsner, M.; Lacrampe-Couloume, G.; Sleep, B.E.; Edwards, E.A.; Sherwood Lollar, B. Effects of trace element concentration on enzyme controlled stable isotope fractionation during aerobic biodegradation of toluene. Environ. Sci. Technol. 2006, 40, $7675-7681$ 
40. Penning, H.; Cramer, C.J.; Elsner, M. Rate-dependent carbon and nitrogen kinetic isotope fractionation in hydrolysis of isoproturon. Environ. Sci. Technol. 2008, 42, 7764-7771

41. Renpenning, J.; Keller, S.; Cretnik, S.; Shouakar-Stash, O.; Elsner, M.; Schubert, T.; Nijenhuis, I. Combined $\mathrm{C}$ and $\mathrm{Cl}$ isotope effects indicate differences between corrinoids and enzyme (Sulfurospirillum multivorans PceA) in reductive dehalogenation of tetrachloroethene, but not trichloroethene. Environ. Sci. Technol. 2014, 48, 11837-11845

42. Renpenning, J.; Rapp, I.; Nijenhuis, I. Substrate hydrophobicity and cell composition influence the extent of rate limitation and masking of isotope fractionation during microbial reductive dehalogenation of chlorinated ethenes. Environ. Sci. Technol. 2015, 49, 4293-4301

43. Tobler, N.B.; Hofstetter, T.B.; Schwarzenbach, R.P. Carbon and hydrogen isotope fractionation during anaerobic toluene oxidation by Geobacter metallireducens with different Fe(III) phases as terminal electron acceptors. Environ. Sci. Technol. 2008, 42, 7786-7792

44. Vogt, C.; Cyrus, E.; Herklotz, I.; Schlosser, D.; Bahr, A.; Herrmann, S.; Richnow, H.H.; Fischer, A. Evaluation of toluene degradation pathways by two-dimensional stable isotope fractionation. Environ. Sci. Technol. 2008, 42, 7793-7800

45. Abe, Y.; Aravena, R.; Zopfi, J.; Shouakar-Stash, O.; Cox, E.; Roberts, J.D.; Hunkeler, D. Carbon and chlorine isotope fractionation during aerobic oxidation and reductive dechlorination of vinyl chloride and cis-1,2-dichloroethene. Environ. Sci. Technol. 2009, 43, 101-107

46. Audí-Miró, C.; Cretnik, S.; Otero, N.; Palau, J.; Shouakar-Stash, O.; Soler, A.; Elsner, M. Cl and $\mathrm{C}$ isotope analysis to assess the effectiveness of chlorinated ethene degradation by zerovalent iron: Evidence from dual element and product isotope values. Appl. Geochem. 2013, 32, $175-183$

47. Cretnik, S.; Thoreson, K.A.; Bernstein, A.; Ebert, K.; Buchner, D.; Laskov, C.; Haderlein, S.; Shouakar-Stash, O.; Kliegman, S.; McNeill, K.; Elsner, M. Reductive dechlorination of TCE by chemical model systems in comparison to dehalogenating bacteria: Insights from dual element isotope analysis $\left({ }^{13} \mathrm{C} /{ }^{12} \mathrm{C},{ }^{37} \mathrm{Cl} /{ }^{35} \mathrm{Cl}\right)$. Environ. Sci. Technol. 2013, 47, 6855-6863 
48. Kuder, T.; van Breukelen, B.M.; Vanderford, M.; Philp, P. 3D-CSIA: Carbon, chlorine, and hydrogen isotope fractionation in transformation of TCE to ethene by a Dehalococcoides culture. Environ. Sci. Technol. 2013, 47, 9668-9677

49. Badin, A.; Buttet, G.; Maillard, J.; Holliger, C.; Hunkeler, D. Multiple dual C-Cl isotope patterns associated with reductive dechlorination of tetrachloroethene. Environ. Sci. Technol. 2014, 48, 9179-9186

50. Palau, J; Cretnik, S.; Shouakar-Stash, O.; Höche, M.; Elsner, M.; Hunkeler, M. C and Cl isotope fractionation of 1,2-dichloroethane displays unique $\delta^{13} \mathrm{C} / \delta^{37} \mathrm{Cl}$ patterns for pathway identification and reveals surprising $\mathrm{C}-\mathrm{Cl}$ bond involvement in microbial oxidation. Environ. Sci. Technol. 2014, 48, 9430-9437

51. Poulson, S.R.; Drever, J.I. Stable isotope $(\mathrm{C}, \mathrm{Cl}$, and $\mathrm{H})$ fractionation during vaporization of trichloroethylene. Environ. Sci. Technol. 1999, 33, 3689-3694

52. Slater, G.F.; Ahad, J.M.E.; Sherwood Lollar, B.; Allen-King, R.M.; Sleep, B.E. Carbon isotope effects resulting from equilibrium sorption of dissolved VOCs. Anal. Chem. 2000, 72, 56695672

53. Wang, Y.; Huang, Y.S. Hydrogen isotopic fractionation of petroleum hydrocarbons during vaporization: Implications for assessing artificial and natural remediation of petroleum contamination. Appl. Geochem. 2003, 18, 1641-1651

54. Bouchard, D.; Hohener, P.; Hunkeler, D. Carbon isotope fractionation during volatilization of petroleum hydrocarbons and diffusion across a porous medium: a column experiment. Environ. Sci. Technol. 2008, 42, 7801-7806

55. Kuder, T.; Philp, P.; Allen, J. Effects of volatilization on carbon and hydrogen isotope ratios of MTBE. Environ. Sci. Technol. 2009, 43, 1763-1768

56. Jeannottat, S.; Hunkeler, D. Chlorine and carbon isotopes fractionation during volatilization and diffusive transport of trichloroethene in the unsaturated zone. Environ. Sci. Technol. 2012, 46, 3169-3176 
57. Wanner, P.; Hunkeler, D. Carbon and chlorine isotopologue fractionation of chlorinated hydrocarbons during diffusion in water and low permeability sediments. Geochim. Cosmochim. Acta 2015, 157, 198-212

58. Hunkeler, D.; Meckenstock, R. U.; Sherwood Lollar, B.; Schmidt, T.; Wilson, J.; Schmidt, T.; Wilson, J. A guide for assessing biodegradation and source identification of organic ground water contaminants using compound specific isotope analysis (CSIA); PA 600/R-08/148; US EPA: 2008; www.epa.gov/ada

59. Van Breukelen, B.M. Extending the Rayleigh equation to allow competing isotope fractionating pathways to improve quantification of biodegradation. Environ. Sci. Technol. 2007, 41, 40044010

60. Hunkeler, D.; Abe, Y.; Broholm, M.M.; Jeannottat, S.; Westergaard, C.; Jacobsen, C.S.; Aravena, R.; Bjerg, P.L. Assessing chlorinated ethene degradation in a large scale contaminant plume by dual carbon-chlorine isotope analysis and quantitative PCR. J. Contam. Hydrol. 2011, $119,69-79$

61. Wiegert, C.; Aeppli, C.; Knowles, T.; Holmstrand, H.; Evershed, R.; Pancost, R.D. ; Macháčková, J.; Gustafsson, O. Dual carbon-chlorine stable isotope investigation of sources and fate of chlorinated ethenes in contaminated groundwater. Environ. Sci. Technol. 2012, 46, 10918-10925

62. Audí-Miró, C.; Cretnik, S.; Torrentó, C.; Rosell, M.; Shouakar-Stash, O.; Otero, N.; Palau, J.; Elsner, M.; Soler, A. C, $\mathrm{Cl}$ and $\mathrm{H}$ compound-specific isotope analysis to assess natural versus $\mathrm{Fe}(0)$ barrier-induced degradation of chlorinated ethenes at a contaminated site. J. Hazard. Mater. 2015, 299, 747-754

63. Badin, A.; Broholm, M.M.; Jacobsen, C.S.; Palau, J.; Dennis, P.; Hunkeler, D. Identification of abiotic and biotic reductive dechlorination in a chlorinated ethene plume after thermal source remediation by means of isotopic and molecular biology tools. J. Contam. Hydrol. 2016, 192, 119 
64. Palau, J.; Jamin, P. ; Badin, A. ; Vanhecke, N.; Haerens, B.; Brouyère, S.; Hunkeler, D. Use of carbon-chlorine dual isotope analysis to assess the degradation pathways of 1,1,1trichloroethane in groundwater. Water Res. 2016, 92, 235-243

65. Palau, J.; Shouakar-Stash, O.; Hunkeler, D. Carbon and chlorine isotope analysis to identify abiotic degradation pathways of 1,1,1-trichloroethane. Environ. Sci. Technol. 2014, 48, 1440014408

66. Breider, F.; Hunkeler, D. Investigating chloroperoxidase-catalyzed formation of chloroform from humic substances using stable chlorine isotope analysis. Environ. Sci. Technol. 2014, 48, $1592-1600$

67. Heckel, B.; Rodríguez-Fernández, D.; Torrentó, D.; Meyer, A.; Palau, J.; Domènech, C.; Rosell, M.; Soler, A.; Hunkeler, D.; Elsner, D. Compound-specific chlorine isotope analysis of tetrachloro-methane and trichloromethane by GC-IRMS vs. GC-qMS: Method development and evaluation of precision and trueness. Anal. Chem. 2017, 89, 3411-3420

68. Marchesi, M.; Aravena, R.; Sra, K.S.; Thomson, N.R.; Otero, N.; Soler, A.; Mancini, S. Carbon isotope fractionation of chlorinated ethenes during oxidation by Fe2+ activated persulfate. Sci. Total Environ. 2012, 433, 319-322

69. Marchesi, M.; Thomson, N. R.; Aravena, R.; Sra, K. S.; Otero, N.; Soler, A. Carbon isotope fractionation of 1,1,1-trichloroethane during base-catalyzed persulfate treatment. J. Hazard. Mater. 2013, 260, 61-66

70. Farrell, J.; Kason, M.; Melitas, N.; Li, T. Investigation of the long-term performance of zerovalent iron for reductive dechlorination of trichloroethylene. Environ. Sci. Technol. 2000, 34, $514-521$

71. Neumann, A.; Hofstetter, T.B.; Skarpeli-Liati, M.; Schwarzenbach, R.P. Reduction of polychlorinated ethanes and carbon tetrachloride by structural Fe(II) in smectites. Environ. Sci. Technol. 2009, 43, 4082-4089

72. Gu, X.G.; Lu, S.G.; Li, L.; Qiu, Z.F.; Sui, Q.; Lin, K.F.; Luo, Q.S. Oxidation of 1,1,1trichloroethane stimulated by thermally activated persulfate. Ind. Eng. Chem. Res. 2011, 50, $11029-11036$ 
73. Xu, M.H.; Gu, X.G.; Lu, S.G.; Qiu, Z.F.; Sui, Q. Role of reactive oxygen species for 1,1,1trichloroethane degradation in a thermally activated persulfate system. Ind. Eng. Chem. Res. 2014, 53, 1056-1063

74. Hine, J. Carbon dichloride as an intermediate in the basic hydrolysis of chloroform. A mechanism for substitution reactions at a saturated carbon atom. J. Am. Chem. Soc. 1950, 72, $2438-2445$

75. Fells, I.; Moelwyn-Hughes, E.A. The kinetics of the hydrolysis of the chlorinated methanes. J. Chem. Soc. 1959, 398-409

76. Hine, J.; Ehrenson, S.J. The effect of structure on the relative stability of dihalomethylenes. $J$. Am. Chem. Soc. 1958, 80, 824-830

77. Valiev, M.; Garrett, B.C.; Tsai, M.-K.; Kowalski, K.; Kathmann, S.M.; Schenter, G.K.; Dupuis, M. Hybrid approach for free energy calculations with high-level methods: Application to the $\mathrm{S}_{\mathrm{N}} 2$ reaction of $\mathrm{CHCl}_{3}$ and $\mathrm{OH}^{-}$in water. J. Chem. Phys. 2007, 127, 051102-1-4

78. Aelion, C.M.; Hohëner, P.; Hunkeler, D.; Aravena, R. Environmental isotopes in biodegradation and bioremediation; CRC Press: Boca Raton, FL, 450 p, 2010

79. Skell, P.S.; Hauser, C.R. The mechanism of beta-elimination with alkyl halides. J. Am. Chem. Soc. 1945, 67, 1661-1661

80. Zwank, L.; Elsner, M.; Aeberhard, A.; Schwarzenbach, R.P. Carbon isotope fractionation in the reductive dehalogenation of carbon tetrachloride at iron (hydr)oxide and iron sulfide minerals. Environ. Sci. Technol. 2005, 39, 5634-5641

81. Bernstein, A.; Shouakar-Stash, O.; Ebert, K.; Laskov, C.; Hunkeler, D.; Jeannottat, S.; Sakaguchi-Sader, K.; Laaks, J.; Jochmann, M.A.; Cretnik, S.; Jager, J.; Haderlein, S.B.; Schmidt, T.C.; Aravena, R.; Elsner, M. Compound-specific chlorine isotope analysis: A comparison of gas chromatography/isotope ratio mass spectrometry and gas chromatography/quadrupole mass spectrometry methods in an interlaboratory study. Anal. Chem. 2011, 83, 7624-7634 
82. Sutton, N.B.; Grotenhuis, J.T.C.; Langenhoff, A.A.M.; Rijnaarts, H.H.M. Efforts to improve coupled in situ chemical oxidation with bioremediation: a review of optimization strategies. $J$. Soils Sediments 2011, 11, 129-140

83. Weathers, L.J.; Parkin, G.F.; Alvarez, P.J. Utilization of cathodic hydrogen as electron donor for chloroform cometabolism by a mixed, methanogenic culture. Environ. Sci. Technol. 1997, 31, $880-885$

84. Novak, P.; Daniels, L.; Parkin, G. Enhanced dechlorination of carbon tetrachloride and chloroform in the presence of elemental iron and Methanosarcina barkeri, Methanosarcina thermophila, or Methanosaeta concillii. Environ. Sci. Technol. 1998, 32, 1438-1443

85. Gregory, K.B.; Mason, M.G.; Picken, H.D.; Weathers, L.J.; Parkin, G.F. Bioaugmentation of Fe (0) for the remediation of chlorinated aliphatic hydrocarbons. Environ. Eng. Sci. 2000, 17, 169181

86. Támara, M.L; Butler, E.C. Effects of iron purity and groundwater characteristics on rates and products in the degradation of carbon tetrachloride by iron metal. Environ. Sci. Technol. 2004, 38, 1866-1876

87. Becker, J.G.; Freedman, D.L. Use of cyanocobalamin to enhance anaerobic biodegradation of chloroform. Environ. Sci. Technol. 1994, 28, 1942-1949

88. Guerrero-Barajas, C.; Field, J.A. Riboflavin- and cobalamin-mediated biodegradation of chloroform in a methanogenic consortium. Biotechnol. Bioeng. 2005, 89, 539-550 
679 Figure 1. CF degradation kinetics (upper panels) and changes in $\mathrm{C}$ and $\mathrm{Cl}$ isotope ratios (lower

680

681

682

683

684

685

686

687

688

689

690

691

692

693

694

695

696

697

698

699

700

701

702 panels) during oxidation by thermally-activated PS with an initial PS/CF molar ratio of 40/1 (A), alkaline hydrolysis (B) and dechlorination by $\mathrm{Fe}(0)(\mathrm{C})$. Data from duplicate experiments (A and B parallel series) and from control (CTRL) experiments are shown. In the upper panels, the error bars show the uncertainty in of $\mathrm{C} / \mathrm{C}_{0}$, calculated by error propagation including uncertainty in concentration measurements. In some cases, error bars are smaller than the symbols. k' values were obtained from curve fittings according to Eq. SI4 (see Fig S1). Fits were conducted with liner regressions in Sigma Plot 10.0 for Windows. Dashed lines represent 95\% CI of regression. For CF dechlorination with $\mathrm{Fe}(0), \mathrm{k}$ ' was calculated omitting data after 30 days when the disappearance of CF almost stopped. In the lower panels, error bars of individual data points indicate standard deviations of the measurements. In most cases, error bars are smaller than the symbols.

Figure 2. Logarithmic plots according to Rayleigh equation (Eq. 1) of carbon (left panels) and chlorine (right panels) isotope ratios during CF oxidation by thermally-activated PS (A and B), alkaline hydrolysis (C and D) and dechlorination by $\mathrm{Fe}(0)$ ( $E$ and F). Data from duplicate experiments were used for estimating $\varepsilon_{\mathrm{C}}$ and $\varepsilon_{\mathrm{Cl}}$. Dashed lines represent 95\% CI of the linear regression. Error bars display the uncertainty calculated by error propagation including uncertainties in concentration and isotope measurements. In some cases, error bars are smaller than the symbols.

Figure 3. (A) Proposed reaction pathways for CF degradation by the three studied reactions. More details are given in the SI. (B) Dual C-Cl isotope plot for CF degradation by the three studied pathways: oxidation by thermally-activated PS (PS), alkaline hydrolysis (AH) and dechlorination by $\mathrm{Fe}(0)(\mathrm{Fe}(0))$. Data from duplicate experiments were combined. Lines are linear regressions of the data sets with 95\% CI (dashed lines). Error bars show uncertainty in isotope measurements. Note that error bars of $\delta^{13} \mathrm{C}$ values are smaller than the symbols. 
704

705

706

707

708

709

710

711

712

713

\begin{tabular}{|c|c|c|c|c|c|c|c|c|}
\hline Experiment & $\begin{array}{l}\text { Reaction } \\
\text { mechanism }\end{array}$ & $\begin{array}{c}\mathcal{E}_{\text {bulkC }} \\
(\%)\end{array}$ & $\mathbf{R}^{2}$ & AKIE $_{C}$ & $\begin{array}{c}\varepsilon_{\text {bulkCl }} \\
(\%)\end{array}$ & $\mathbf{R}^{2}$ & $\mathrm{AKIE}_{\mathrm{Cl}}$ & $\Lambda$ \\
\hline Persulfate & $\begin{array}{l}\text { Oxidative C-H } \\
\text { bond cleavage }\end{array}$ & $-8 \pm 1$ & 0.94 & $\begin{array}{c}1.008 \pm \\
0.001\end{array}$ & $\begin{array}{l}-0.44 \\
\pm 0.06\end{array}$ & 0.97 & $\begin{array}{l}1.00045 \pm \\
0.00004^{\mathrm{a}}\end{array}$ & $17 \pm 2$ \\
\hline $\begin{array}{l}\text { Alkaline } \\
\text { hydrolysis }\end{array}$ & $\begin{array}{c}\mathrm{E} 1_{\mathrm{CB}} \\
\text { elimination }\end{array}$ & $-57 \pm 5$ & 0.97 & $\begin{array}{l}1.061 \pm \\
0.006\end{array}$ & $\begin{array}{c}-4.4 \pm \\
0.4\end{array}$ & 0.96 & $\begin{array}{c}1.0133 \pm \\
0.0004\end{array}$ & $\begin{array}{c}13.0 \pm \\
0.8\end{array}$ \\
\hline $\mathrm{Fe}(0)$ & $\begin{array}{c}\text { Reductive } \\
\text { dechlorination } \\
\text { by } \mathrm{C}-\mathrm{Cl} \text { bond } \\
\text { cleavage }\end{array}$ & $-33 \pm 11$ & 0.82 & $\begin{array}{l}1.034 \pm \\
0.012\end{array}$ & $-3 \pm 1$ & 0.85 & $\begin{array}{c}1.008 \pm \\
0.001\end{array}$ & $8 \pm 2$ \\
\hline
\end{tabular}

Table 1. Carbon and chlorine isotope fractionation ( $\varepsilon_{\mathrm{C}}$ and $\varepsilon_{\mathrm{Cl}}$, respectively), apparent kinetic isotope effects ( $A K I E_{C}$ and $A K I E_{C l}$, respectively) and dual isotope slopes $\left(\Lambda=\Delta \delta^{13} \mathrm{C} / \Delta \delta^{37} \mathrm{Cl}\right)$ values obtained for the three studied CF transformation pathways: oxidation with thermally-activated PS, alkaline hydrolysis and $\mathrm{Fe}(0)$-based reductive dechlorination. The uncertainty of $\varepsilon$, AKIE and $\Lambda$ values corresponds to the 95\% CI. In all cases, AKIE $_{\mathrm{C}}$ was calculated using $\mathrm{x}=\mathrm{z}=1$ in Eq. SI6. For both alkaline hydrolysis and dechlorination by $\mathrm{Fe}(0), \mathrm{AKIE}_{\mathrm{Cl}}$ was calculated using $\mathrm{x}=\mathrm{z}=3$ as all C-Cl bonds are equivalent and compete for reaction. For oxidation with PS, as there is not primary chlorine isotopic effect, the secondary $\mathrm{AKIE}_{\mathrm{Cl}}$ was also calculated by Eq. SI6 using in this case $\mathrm{x}=3$ and $\mathrm{z}=1$ because no specific bond containing $\mathrm{Cl}$ is broken, and there is, therefore, no intramolecular competition for this bond.

\footnotetext{
${ }^{\mathrm{a}}$ secondary isotope effect
} 

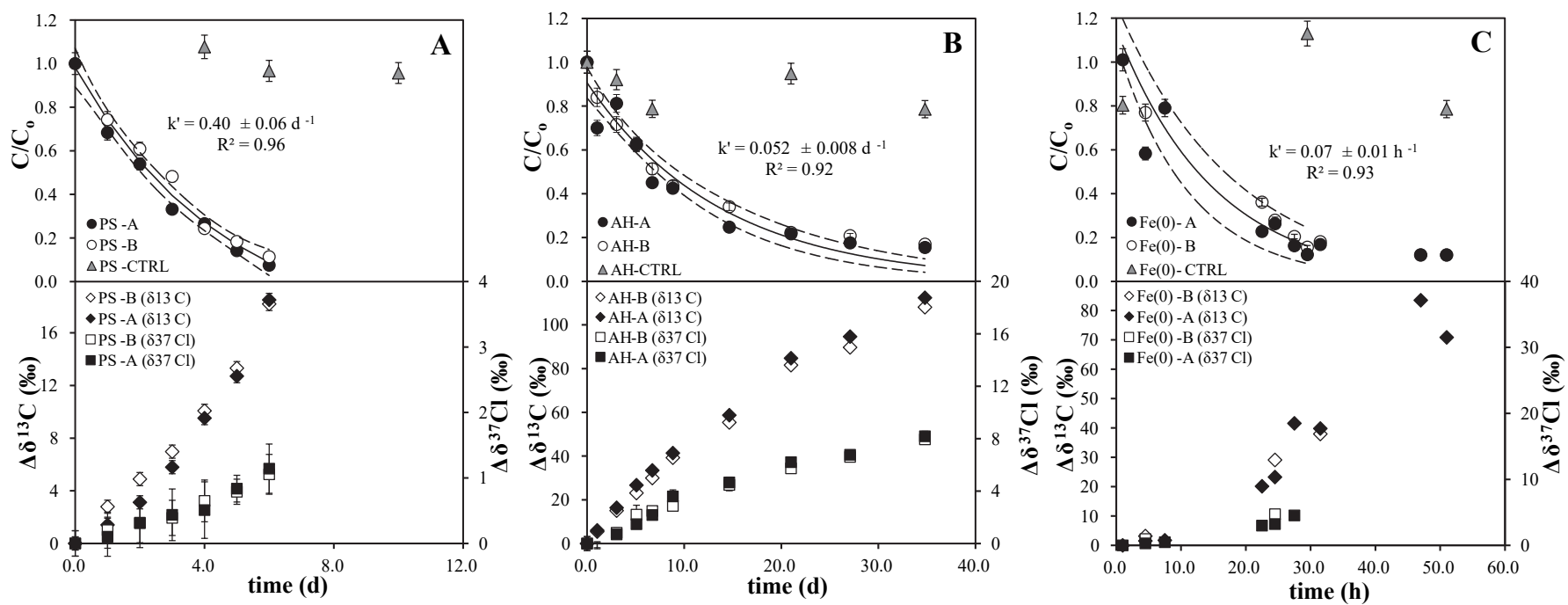

Figure 1. $\mathrm{CF}$ degradation kinetics (upper panels) and changes in $\mathrm{C}$ and $\mathrm{Cl}$ isotope ratios (lower panels) during oxidation by thermally-activated PS with an initial PS/CF molar ratio of 40/1 (A), alkaline hydrolysis (B) and dechlorination by $\mathrm{Fe}(0)(\mathrm{C})$. Data from duplicate experiments (A and B parallel series) and from control (CTRL) experiments are shown. In the upper panels, the error bars show the uncertainty in of $\mathrm{C} / \mathrm{C} 0$, calculated by error propagation including uncertainty in concentration measurements. In some cases, error bars are smaller than the symbols. k' values were obtained from curve fittings according to Eq. SI4 (see Fig S1). Fits were conducted with liner regressions in Sigma Plot 10.0 for Windows. Dashed lines represent $95 \% \mathrm{CI}$ of regression. For $\mathrm{CF}$ dechlorination with $\mathrm{Fe}(0)$, k' was calculated omitting data after 30 days when the disappearance of CF almost stopped. In the lower panels, error bars of individual data points indicate standard deviations of the measurements. In most cases, error bars are smaller than the symbols. 

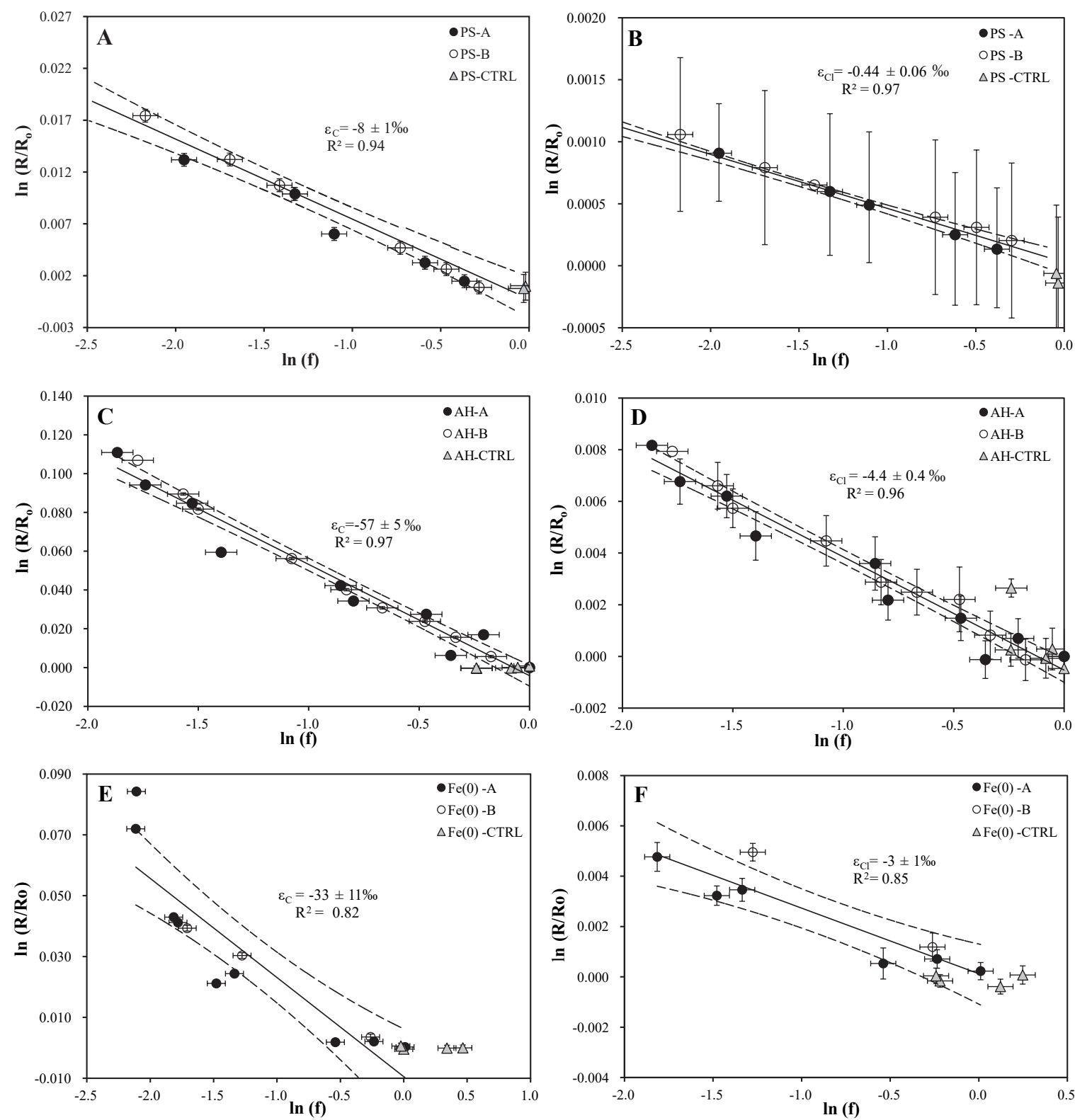

Figure 2. Logarithmic plots according to Rayleigh equation (Eq. 1) of carbon (left panels) and chlorine (right panels) isotope ratios during CF oxidation by thermally-activated PS (A and $B)$, alkaline hydrolysis $(C$ and $D)$ and dechlorination by $\mathrm{Fe}(0)(\mathrm{E}$ and $\mathrm{F})$. Data from duplicate experiments were used for estimating $\varepsilon \mathrm{C}$ and $\varepsilon \mathrm{Cl}$. Dashed lines represent $95 \% \mathrm{CI}$ of the linear regression. Error bars display the uncertainty calculated by error propagation including uncertainties in concentration and isotope measurements. In some cases, error bars are smaller than the symbols. 
FIGURE 3

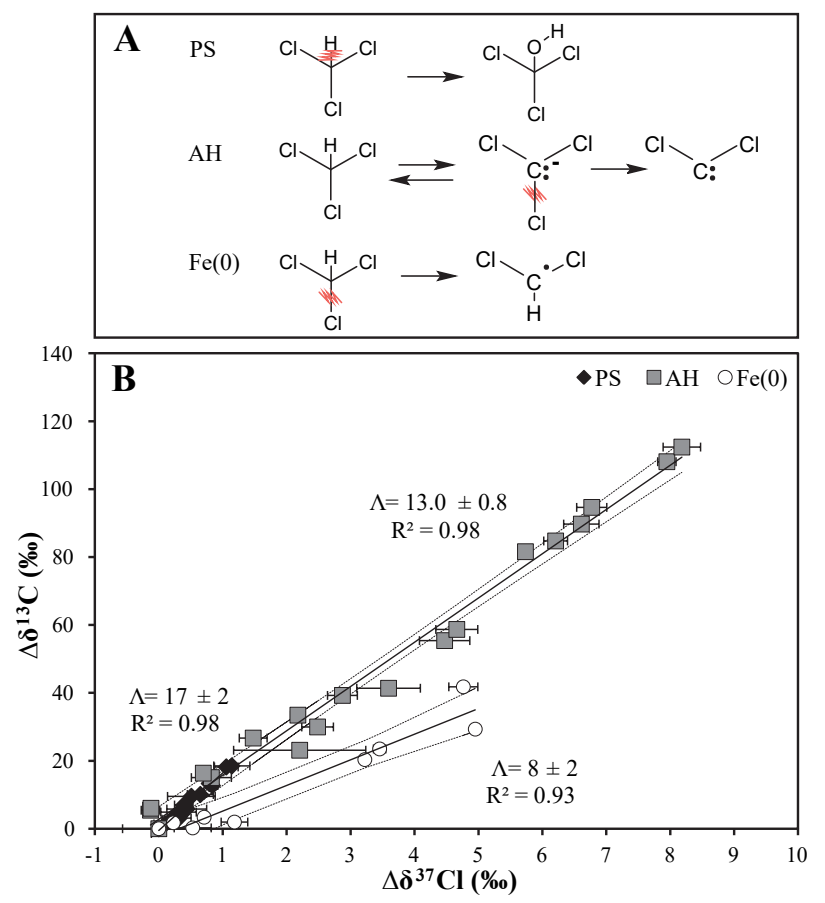

Figure 3. (A) Proposed reaction pathways for $\mathrm{CF}$ degradation by the three studied reactions. More details are given in the SI. (B) Dual C-Cl isotope plot for CF degradation by the three studied pathways: oxidation by thermally-activated PS (PS), alkaline hydrolysis (AH) and dechlorination by $\mathrm{Fe}(0)(\mathrm{Fe}(0))$. Data from duplicate experiments were combined. Lines are linear regressions of the data sets with $95 \%$ CI (dashed lines). Error bars show uncertainty in isotope measurements. Note that error bars of $\delta^{13} \mathrm{C}$ values are smaller than the symbols. 